\title{
Controlled release of 5-flurouracil from biomedical polyurethanes
}

\author{
REDDY SEETHARAMAREDDY HARISHA ${ }^{\mathrm{a}}$, KALLAPPA MAHADEVAPPA HOSAMANI ${ }^{\mathrm{a}, *}$, \\ RANGAPPA SANGAPPA KERI ${ }^{\mathrm{a}}$, NAMDEV SHELKE ${ }^{\mathrm{b}}$, VIJAY KUMAR WADI ${ }^{\mathrm{b}}$ and \\ TEJARAJ M AMINABHAVI ${ }^{\mathrm{b}}$ \\ ${ }^{a}$ P.G. Department of Studies in Chemistry, Karnatak University, Pavate Nagar, Dharwad 580003 \\ ${ }^{\mathrm{b}}$ Drug Delivery Division, Center of Excellence in Polymer Science, Karnatak University, \\ Pavate Nagar, Dharwad 580003 \\ e-mail: dr_hosamani@yahoo.com
}

MS received 11 June 2008; revised 7 November 2009; accepted 25 November 2009

\begin{abstract}
Novel biodegradable aliphatic poly(ether-urethane)s (PEUs) based on pluronic F-68 (PLF68) and castor oil were synthesized by the solution polymerization technique. These polymers were characterized by Fourier transform infrared spectroscopy (FTIR), nuclear magnetic spectroscopy $\left({ }^{1} \mathrm{HNMR}\right)$ and gel permeation chromatography (GPC) to confirm the PEU formation and the molecular weight. Moderate molecular weight PEUs were obtained and converted into microspheres by solvent evaporation method to study the controlled release (CR) characteristics for 5-flurouracil (5-FU). PLF-68 acts as amphiphilic filler, which enhances the release of a hydrophobic drug such as 5-FU. Sizes of the microspheres as measured by laser light scattering technique ranged between 15 and $42 \mu \mathrm{m}$. An increase in the size of particles was observed with increasing molar ratio of PLF-68 with respect to castor oil. The percentage encapsulation efficiency varied between 71 and 98. Surface morphology of the microspheres as studied by scanning electron microscopy (SEM) revealed the spherical nature of the particles with wrinkles on their surfaces. The release of 5-FU through the microspheres was investigated in $\mathrm{pH} 7 \cdot 4-$ phosphate buffer. An increase in release rate was observed with increasing molar ratio of PLF68 with respect to castor oil.
\end{abstract}

Keywords. Biomedical polyurethane; controlled release; 5-flurouracil; drug delivery.

\section{Introduction}

Polyurethanes are one of the most versatile materials in the world today. They are known for being a perfect material for medical devices. ${ }^{1}$ Polyurethanes are commonly used as biomaterials because of their superior physical and mechanical properties ${ }^{2}$ with applications such as contact lens materials ${ }^{3}$ catheters, and drug delivery systems. ${ }^{4,5}$ Therefore, novel polyurethanes are continually being developed to increase their biocompatibility, often by incorporating hydrophilic materials into the polymer, such as poly(ethylene oxide) (PEOs), ${ }^{6}$ or producing polymers that bind heparin or albumin. ${ }^{7,8}$ The properties of polyurethane block copolymers may be modified by changing the composition of the alternating hard and soft segments of the polymer. The soft segment determines the elasticity and hydrophilicity of the

\footnotetext{
*For correspondence
}

polymer and thus affects the polymer's biocompatibility.

The macromonomer Pluronic F-68 used in this study is having biomedical applications and it has been approved for biomedical applications by US food and drug administration. The properties of amphiphilic poly(ethylene oxide)-b-poly-(propylene oxide)-b-poly(ethylene oxide) (PEO-PPO-PEO) block copolymers in aqueous media have attracted a great deal of interest because of several important aspects, ${ }^{9-13}$ (i) PEO-PPO-PEO copolymers are commercially available surfactants (pluronics, synperonics, poloxamers), whose molecular weight and PEO/PPO composition ratio vary within a wide range; (ii) in water they usually spontaneously form nanosized core-shell micelles having a hydrophobic core composed predominantly of PPO segments and a shell dominated by hydrated PEO segments; (iii) the PEO-PPO-PEO copolymers are recognized pharmaceutical excipients listed in the US and the British Pharmacopoeia; (iv) the PEO blocks have 
available functionality to which receptor-specific ligands could be attached. That is why the PEOPPO-PEO copolymers meet the specific requirements for various applications, such as dispersion stabilization, emulsification, detergency, foaming, lubrication, ${ }^{9}$ etc. Presently, the PEO-PPO-PEO copolymers are being intensively evaluated as potential drug and gene delivery systems for multiple pharmaceutical applications as well as for diagnostic imaging as carriers for various contrasting agents. ${ }^{11,13,14}$ The hydrophobic PPO core may serve as a container for waterinsoluble drugs while the hydrophilic PEO shell provides steric stability. ${ }^{15}$ Moreover, PEO is resistant to protein absorption and cellular adhesion thus providing an effective protection of the core content against hydrolysis and enzymatic degradation. In addition, the PEO shell prevents the reticuloendothelial system from recognizing and thus from eliminating the polymeric carriers from the blood stream at an early stage. ${ }^{16,17}$

Multiple hydroxyl functionality is required for the natural oils to be used as convenient raw material for polyurethane production. Hydroxyl functionality occurs naturally in castor oil. Thus, castor oil acts as a polyol which reacts with polyfunctional isocyanates to form polyurethanes whose properties range from rigid polymers to elastomers. ${ }^{18,19}$ The oil contains mainly esters of 12-hydroxy-9-octadecanoic acid $^{20,21}$ thus the presence of hydroxyl groups makes the oil suitable for use in urethane type reactions. Also, the hydrogen bonding of its hydroxyl group confers a high viscosity on the oil. ${ }^{21,22}$ Although the oil is not edible, it is widely used as a starting material for many industrial products. Castor oil has been used in isocyanate reactions to make polyurethane elastomers, ${ }^{23}$ millable, ${ }^{24}$ castable ${ }^{25,26}$ applicable as adhesives and coatings, ${ }^{27,28}$ and as polyurethane foams.$^{29}$ Its competitiveness in relation to other polymers is basically tied to three factors: it derives from a natural and renewable raw material, its mechanical properties are superior to those of petroleum-derived polymers, and the cost of the diisocyanates is reasonable.

A thorough literature survey reveals the lack of literature on the systematic study of natural polyol (castor oil) based diol chain extended PEUs for drug delivery. Hence, this kind of research work was taken, which would give some input to biomedical application of synthetic polymers and design PEUs for medical and pharmaceutical applications. Realizing this importance, in the present study, two monomers viz. castor-oil and Pluronic F-68 were used as diols to prepare the PEUs. The polymers prepared were further developed as microspheres for the controlled release (CR) of a model anticancer drug, viz. 5-flurouracil (5-FU). The in vitro release studies have been performed in $7.4 \mathrm{pH}$ phosphate buffer at $37^{\circ} \mathrm{C}$. The kinetics of drug release was evaluated using an empirical equation. The prepared microspheres as well as the drug loaded microspheres were characterized using different techniques to understand the formation of microparticles, surface morphology as well as their chemical interaction with drug and their sizes.

\section{Experimental}

\subsection{Materials}

Analytical grade castor oil, $N, N$-dimethyl formamide (DMF), dichloromethane (DCM) and poly vinyl alcohol (PVA) of molecular weight 1,25,000 were purchased from S.D. fine chemicals, Mumbai, India. 5-fluorouracil (5-FU) was procured from Loba Chemicals, Mumbai, India. 1,1-methylenebis(dicyclohexyl-4,4-diisocyanate) $\left({ }^{12} \mathrm{H}-\mathrm{MDI}\right)$, Pluronic (PLF68, $\left.M_{\mathrm{W}}=8,400\right), 1,4$-butanediol and dibutyl tin dilaurate were purchased from Aldrich Chemical Company, Milwaukee, WI, USA. DMF was vacuum distilled and dried over $4 \AA$ molecular sieves. Double distilled water was used throughout the study.

\subsection{Synthesis of poly(ether-urethane)}

Polyurethanes were prepared by the method described before. ${ }^{30}$ Castor oil $(0.002 \mathrm{~mol})$ and PLF68 $(0.0001 \mathrm{~mol})$ were dissolved in DMF taken in a $100 \mathrm{~mL}$ round bottom flask fitted with addition funnel, nitrogen inlet and a guard tube. Dibutyl tin dilaurate $(0.02 \%)$ was added to it and stirred on a magnetic stirrer for about 10-15 min under nitrogen atmosphere. A $0.0042 \mathrm{~mol}$ of ${ }^{12} \mathrm{H}$-MDI was added drop-wise to the above reaction mixture. The reaction mixture was stirred for $30 \mathrm{~min}$ and subsequently, heated at $50^{\circ} \mathrm{C}$ for $2 \mathrm{~h}$ to get the isocyanateterminated PEU. The reaction mixture was cooled to ambient temperature and 1,4-butanediol $(0.0021 \mathrm{~mol})$ was added to isocyanate-terminated PEU as a chain extender. The mixture was again heated at $70^{\circ} \mathrm{C}$ for 3-4 h. After completion of the reaction, the mixture was cooled to ambient temperature; the product was precipitated in distilled water, collected by filtration 


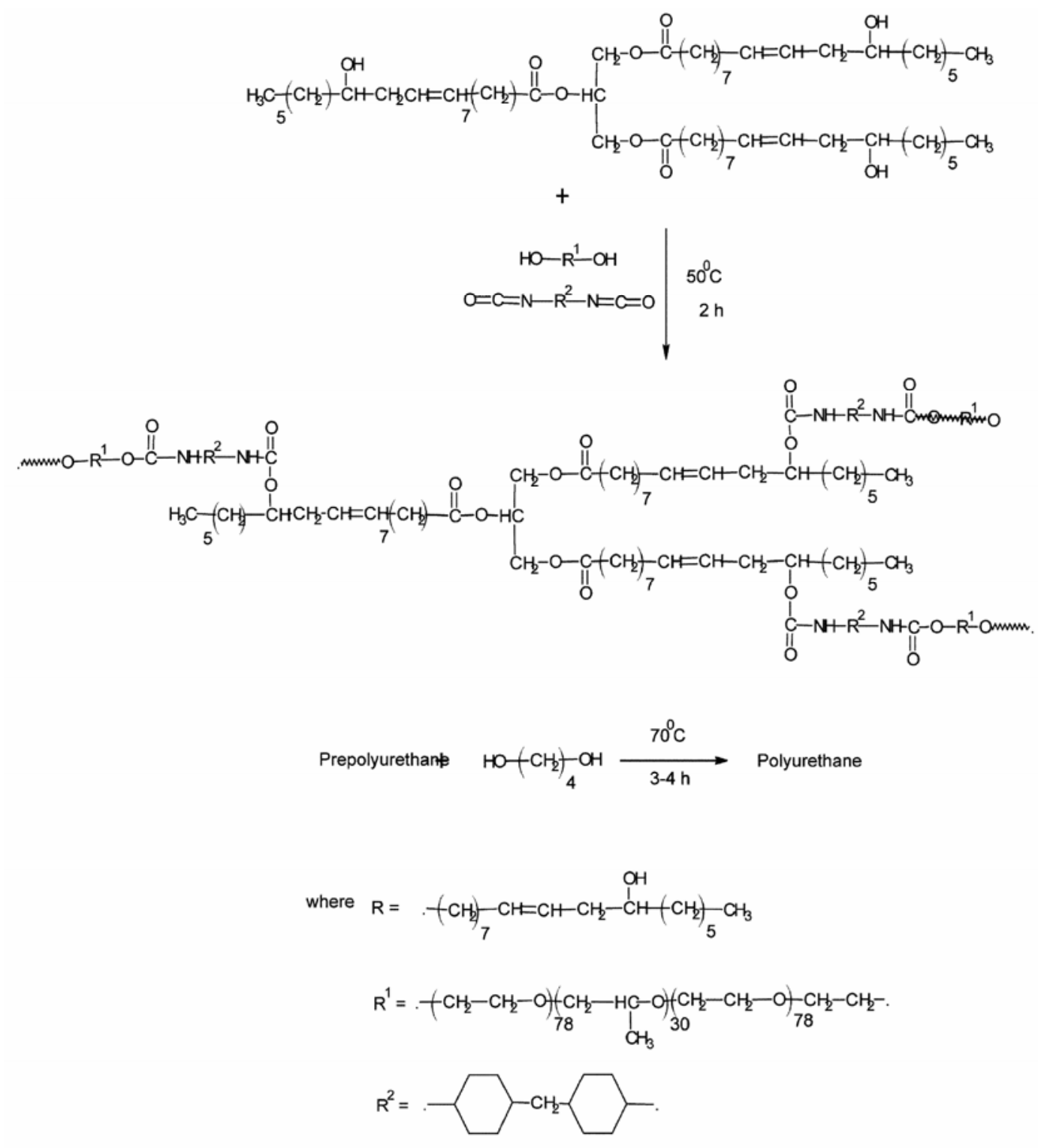

Scheme 1. Synthesis of polyurethane copolymer.

Table 1. Formulation codes and different ratio of monomers used for PEU preparation.

\begin{tabular}{lcc}
\hline Formulation codes & Castor oil (\%) & Pluronic (\%) \\
\hline PEU-99 & 99 & 1 \\
PEU-97 & 97 & 3 \\
PEU-95 & 95 & 5 \\
PEU-93 & 93 & 7 \\
PEU-91 & 91 & 9 \\
\hline
\end{tabular}

and dried in a vacuum oven at $60^{\circ} \mathrm{C}$. Different PEUs were prepared by varying the ratio of PLF68 and castor oil. The formations of PEUs are given in scheme 1, respectively. Formulation codes and dif- ferent ratios of the monomers used for PEU preparation are given in table 1 .

\subsection{Preparation of 5-FU loaded microspheres}

Microspheres of PEUs containing hydrophobic 5-FU drug were prepared by the solvent evaporation technique. Poly(ether-urethane) (100 mg) was dissolved in dichloromethane $(3 \mathrm{~mL})$ followed by the addition of 5 -FU to the polymer $(10: 1)$ at appropriate weight ratio and stirred at the ambient temperature. The polymer/drug solution was added drop-wise to $2.0 \%$ PVA solution under constant stirring using Eurostar high-speed stirrer (IKA Labortechnik, Germany) at 
$800 \mathrm{rpm}$ rotor speed. The solution was further stirred for a period of about $20-30 \mathrm{~min}$ to achieve the complete evaporation of dichloromethane; the solution was then diluted with distilled water and microspheres were isolated using the tabletop centrifuge (Jouan, MR 23i, France). The PEUs microspheres were washed several times by fresh distilled water to remove the adhering particles such as dispersion stabilizers or non encapsulated drugs. The obtained microspheres were redispersed into deionized water and lyophilized by a freeze-dryer (Jouan, LP3, France) to obtain the completely dried microspheres.

\subsection{Drug loading efficiency}

Microspheres loaded with drug were dissolved in DCM and the amount of 5-FU entrapped was determined by UV spectrophotometer (Secomam, Anthelie, France) at the $\lambda_{\max }$ value of $243 \mathrm{~nm}$. These data were collected in triplicate, but average values were considered in calculating percentage drug loading and encapsulation efficiency. The 5-FU content entrapped into the microspheres was calculated using the following equations:

Actual drug loading (\%)

$$
=\left(\frac{\text { Weight of drug in microspheres }}{\text { Weight of microspheres }}\right) \times 100 \text {. }
$$

Percentage of encapsulation efficiency

$$
=\left(\frac{\text { Actual drug loading }}{\text { Theoretical drug loading }}\right) \times 100 .
$$

The results on the amount of 5-FU loading and drug loading efficiency of PEUs are presented in table 2 .

Table 2. Percentage drug loading and drug loading efficiency of $10 \% 5$-FU loaded PEUs.

\begin{tabular}{lcc}
\hline $\begin{array}{l}\text { Formulation } \\
\text { codes }\end{array}$ & $\begin{array}{l}\text { Encapsulation } \\
\text { efficiency }(\%)\end{array}$ & $\begin{array}{c}\text { Microsphere } \\
\text { diameter }(\mu \mathrm{m})\end{array}$ \\
\hline PEU-99 & 98 & $11-13$ \\
PEU-97 & 92 & $14-18$ \\
PEU-95 & 88 & $20-25$ \\
PEU-93 & 81 & $27-32$ \\
PEU-91 & 71 & $35-39$ \\
\hline
\end{tabular}

\subsection{In vitro drug release}

Weighed amounts of drug-loaded microspheres (10 mg) were suspended in $100 \mathrm{~mL}$ of phosphate buffer with $\mathrm{pH} 7 \cdot 4$. Dissolution medium was stirred at $100 \mathrm{rpm}$ at $37^{\circ} \mathrm{C}$ using a water bath with a shaker (Grant OLS200, Grant Instruments, Cambridge Ltd, UK). Aliquots of dissolution medium $(3 \mathrm{~mL})$ were withdrawn and filtered through $0.25 \mathrm{~mm}$ Millipore filter at the predetermined time intervals. After appropriate dilution, drug concentration was analysed by UV spectrophotometer (Secomam, Anthelie, France) at the fixed $\lambda_{\max }$ value of $243 \mathrm{~nm}$. Dissolution medium was maintained at constant volume by replacing the samples with a fresh dissolution medium.

\subsection{Gel permeation chromatography (GPC)}

Molecular weights of the synthesized PEUs were determined by GPC (Viscotek, Houston, TX, USA) attached to a differential refractive index detector (Viscotek, VE 3580) by employing two columns (Viscotek gel, GMHH R-H). The flow rate of the mobile phase, viz. THF was set to $1 \mathrm{~mL} / \mathrm{min}$; polystyrene standards were used for calibration runs. Subsequently, the molecular weight of PEUs was reported as the polystyrene equivalent molecular weight. The results of molecular weight and polydispersity index are given in table 3 .

\subsection{Fourier transform infrared spectra (FTIR)}

FTIR spectra of the polymers were determined using Nicolet 5700 spectrophotometer (Milwaukee, WI, USA) at the spectral range of 4000 to $400 \mathrm{~cm}^{-1}$. Samples were crushed with $\mathrm{KBr}$ to get the pellets under a hydraulic pressure of $600 \mathrm{~kg} / \mathrm{cm}^{2}$.

\subsection{Nuclear magnetic resonance spectroscopy (NMR)}

Nuclear magnetic resonance $\left({ }^{1} \mathrm{H}\right.$ NMR) spectra were recorded on a $300 \mathrm{MHz}$ instrument (Bruker 300 NMR

Table 3. Distribution of molecular weight and polydispersity index.

\begin{tabular}{lcc}
\hline Polymer code & $\mathrm{M}_{\mathrm{w}}$ & $\mathrm{M}_{\mathrm{w}} / \mathrm{M}_{\mathrm{n}}$ \\
\hline PEU-99 & 32,400 & $1 \cdot 22$ \\
PEU-97 & 33,500 & $1 \cdot 23$ \\
PEU-95 & 34,600 & $1 \cdot 24$ \\
PEU-93 & 35,200 & $1 \cdot 25$ \\
PEU-91 & 35,800 & 1.29 \\
\hline
\end{tabular}


spectrometer) using $\mathrm{CDCl}_{3}$ as a solvent and tetramethylsilane as an internal standard. ${ }^{1} \mathrm{H}$ NMR spectra of the PEU containing Pluronic F-68 are shown in figure 2 .

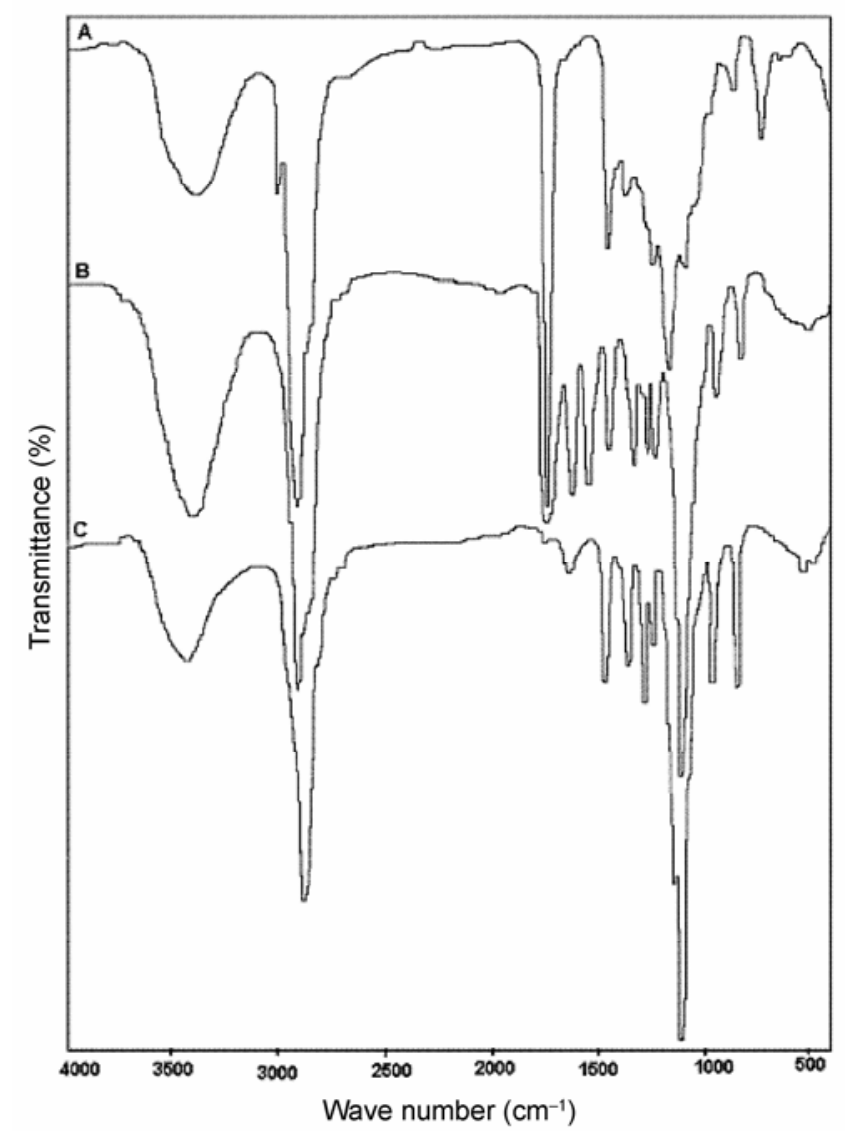

Figure 1. FTIR spectrum of polyurethane prepared from of PLF-68 and castor-oil (A = Castor-oil; B = Polyurethane, $\mathrm{C}=$ PLF-68).

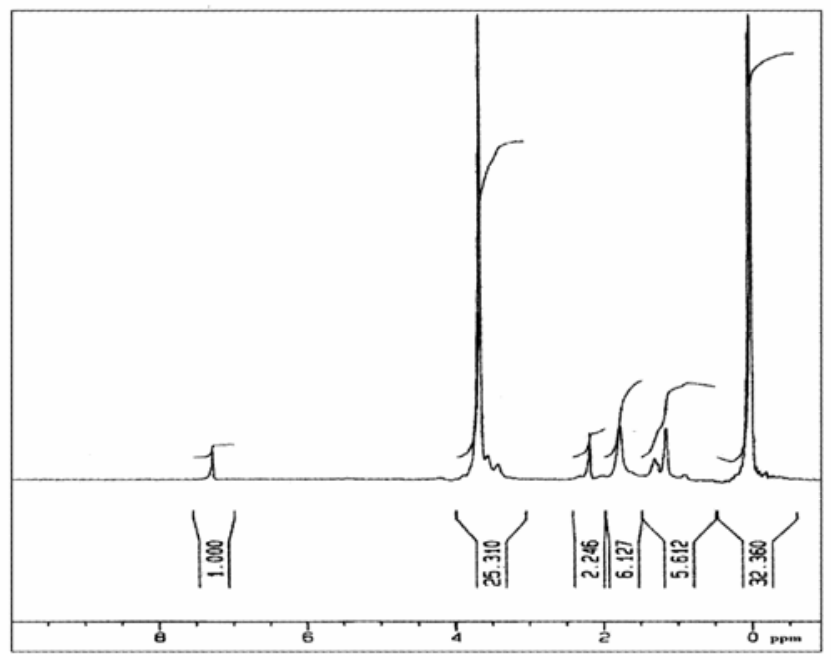

Figure 2. ${ }^{1} \mathrm{H}$ NMR spectrum of polyurethane prepared from of PLF-68 and castor-oil.

\subsection{Scanning electron microscopy (SEM)}

SEM images of the microspheres were recorded using Joel JSM 6400 scanning electron Microscope (Japan) at the required magnification. A thin film of $10 \mathrm{~nm}$ gold coating was done before subjecting the samples to SEM.

\subsection{Particle size analyzer}

Particle size was measured by laser light scattering technique (Mastersizer 2000, Malvern, UK). Sizes of the completely dried microspheres of different formulations were measured using the dry sample adopter. The volume-mean diameter (Vd) was recorded and these results are presented in table 4 .

\section{Results and discussion}

\subsection{Gel permeation chromatography}

The GPC data indicated that molecular weights of the polymers increased with an increase of PLF-68. This suggests an increase in molecular weights of the polymers with increasing molar ratio of PLF-68 with respect to castor oil (table 3). The data on molecular weight and polydispersity index are given in table 3 .

\subsection{Fourier transform infrared spectra (FTIR)}

3.2a Peak assignments for PEUs: The spectrum showed absorption bands at $1719 \mathrm{~cm}^{-1}$ for the carbonyl group of urethane linkage $(-\mathrm{NH}-\mathrm{COO}-)$. The absence of a peak due to isocyanate around $2260 \mathrm{~cm}^{-1}$ indicated a complete reaction between alcohol and isocyanate, resulting in the formation of a urethane linkage. While a broad band located around

Table 4. Exponent value, $n$ for drug loaded PEU microspheres analyzed from the empirical equation of Ritger and Peppas.

\begin{tabular}{lcc}
\hline & \multicolumn{2}{c}{ Power law } \\
\cline { 2 - 3 } Polymer codes & $n$ & $\mathrm{r}^{2}$ \\
\hline PEU-99 & 0.69 & 0.95 \\
PEU-97 & 0.62 & 0.96 \\
PEU-95 & 0.51 & 0.98 \\
PEU-93 & 0.48 & 0.97 \\
PEU-91 & 0.47 & 0.98 \\
\hline
\end{tabular}


$3421 \mathrm{~cm}^{-1}$ is due to $\mathrm{N}-\mathrm{H}$ stretching of the urethane linkage. The peak due to $\mathrm{C}-\mathrm{N}$ stretching vibrations was located around $1557 \mathrm{~cm}^{-1}$. The aliphatic $\mathrm{C}-\mathrm{H}$ stretching vibrations were shown around $2855 \mathrm{~cm}^{-1}$. FT-IR curves are displayed in figure 1.

\subsection{Nuclear magnetic resonance spectroscopy (NMR)}

${ }^{1} \mathrm{H}$ NMR spectra (figure 2) reveal that chemical shifts, $\delta$ observed at $1 \cdot 15,1 \cdot 77,2 \cdot 17,3.55,3.57$ and $3.64 \mathrm{ppm}$ are well resolved, which belong to hydrogen atoms of the individual functional groups on PEU. However, castor oil $-\mathrm{CH}_{3}-$ comes at $\delta=1.15 \mathrm{ppm}$, $-\mathrm{CH}_{2}-\mathrm{CH}_{2}-$ at $\delta=1.77 \mathrm{ppm}$ and $-\mathrm{OC}-\mathrm{CH}_{2}-$ at $\delta=2.17 \mathrm{ppm}$, in the polymer $-\mathrm{NH}-$ at $\delta=3.55 \mathrm{ppm}$ as a $\mathrm{D}_{2} \mathrm{O}$ exchangeable peak. Introducing Pluronic into the polymer causes another chemical shift for methyl protons of Pluronic block $\left(-\mathrm{O}-\mathrm{CH}_{2}-\mathrm{CH}_{2}-\right)$ at $\delta=3.65 \mathrm{ppm},\left(\mathrm{O}-\mathrm{CH}_{2}-\mathrm{CH}\left(\mathrm{CH}_{3}\right)-\right)$ at $\delta=3.57 \mathrm{ppm}$ which confirms the existence of Pluronics F-68 in the PEU segments and absence of $\mathrm{OH}$ proton around $\delta=2-3 \mathrm{ppm}$ complete reaction between alcohol and isocyanate.

\subsection{Scanning electron micrograph (SEM)}

Micrographs of the drug-loaded PEU sample shown in figure 3 and these microspheres are spherical in nature and have wrinkled surfaces.

\subsection{Particle size analysis}

Particle size analysis showed an increasing trend of the microspheres with increasing amount of PLF-68

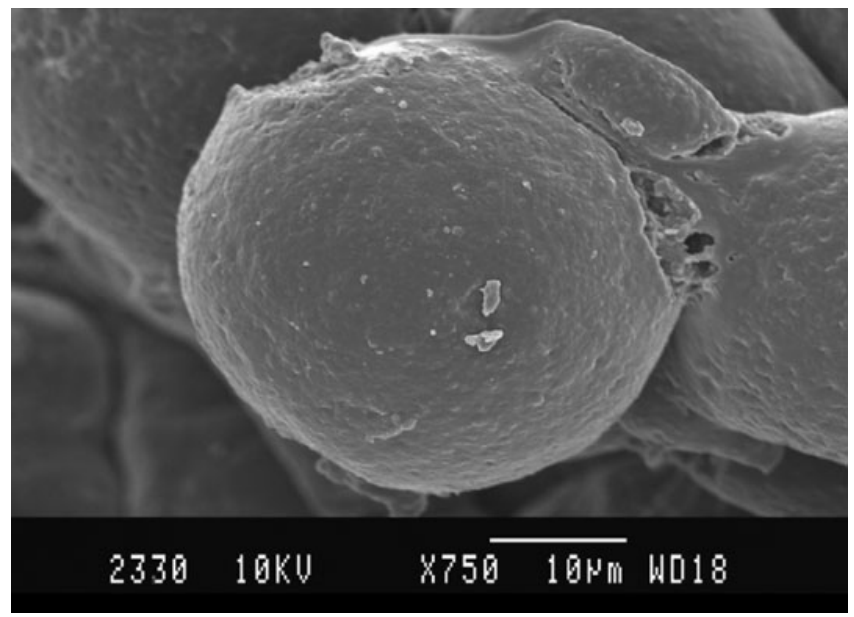

Figure 3. SEM picture of 5-FU-loaded group of microspheres. monomer in the polymers, viz. PEU-99, PEU-97, PEU-95, PEU-93, and PEU-91. The size of microspheres was increased from 11 to $39 \mu \mathrm{m}$. Such an increase in size with respect to increase in PLF-68 of the PEUs is due to high viscosity of PEU in DCM solution. The increase of PLF-68 with respect to castor-oil in PEUs has further increased the molecular weights of PEUs. Also, an increase in the size of microspheres is due to the bulk structure of PLF-68. The microparticles were prepared using a constant stirrer speed of $800 \mathrm{rpm}$ taking $200 \mathrm{mg}$ of the polymer in $6 \mathrm{~mL}$ of DCM.

\subsection{Drug loading efficiency}

Results of percentage of drug loading and percentage of encapsulation efficiency for different formulations are presented in table 2. A fixed amount of drug $(10 \mathrm{wt} \%)$ was used for the initial loading into the PEUs. UV results suggest that percentage, 5-FU loading has decreased as a result of increasing amount of PLF-68 in PEUs. The loadings of 5-FU in PEU-91, PEU-93, PEU-95, PEU-97 and PEU-99 matrices are respectively $7 \cdot 1,8 \cdot 1,8 \cdot 8,9 \cdot 2$ and $9 \cdot 8 \%$. However, the percentage encapsulation efficiency decreased from 98 to 71 with increasing molar ratio of PLF-68 with respect to castor-oil. Significant reductions in the percentage drug loading and percentage encapsulation efficiency data are attributed to hydrophilic nature of PLF-68 and hydrophobic nature of 5-FU present in PEUs.

\subsection{In vitro drug release}

Release characteristics of PLF-68 and castor-oil based PEUs were evaluated to investigate the CR of 5-FU. Plots of release patterns of 5-FU loaded PEU microspheres are displayed in figure 4. No burst effects were observed in all the formulations, since only $7,10,14,18$ and $22 \%$ of 5 -FU drug was released from PEU-91, PEU-93, PEU-95, PEU-97, and PEU-99, respectively during the initial duration of $2 \mathrm{~h}$. However, the release studies were performed up to $120 \mathrm{~h}$ and the amounts of drug released during this time were $71,81,88,92$ and 98 respectively, indicating successful usage of the matrices developed in this study.

\subsection{Drug release kinetics}

The empirical equation, $M_{\mathrm{t}} / M_{\infty}=k t^{n}$ used earlier by Ritger and Peppas ${ }^{31}$ was employed to analyse drug 
release characteristics from both swellable and nonswellable systems. ${ }^{32}$ Fickian diffusion $(n=0.5)$ and Case II transport $(n=1)$ are often observed when drugs are released from such diffusion-controlled and swelling-controlled systems, respectively. Any system that can be controlled both by diffusion and swelling mechanisms usually would offer the $\mathrm{n}$ values in the range $0.5<n<1$. The values of $\mathrm{n}$ were calculated from the slope of the plots of $\ln \left(M_{\mathrm{t}} / M_{\infty}\right)$ vs $\ln t$. The values of $n$ for different PEU microspheres loaded with 5-FU are given in table 4 . The values of $\mathrm{n}$ for formulation PEU-95 are close to $0 \cdot 5$, indicating the Fickian type release pattern, but when the concentration of hydrophilic segments of Pluronic F-68 in copolymers was increased, the value of $\mathrm{n}$ was decreased to 0.47 which indicates the nonFickian trends. The $n$ values greater than 0.5 indicates the anomalous type release trends. Previous studies reported in the literature also suggested similar anomalies..$^{30,33,34}$

\section{Conclusions}

The present study reports the development of novel microspheres of castor-oil and Pluronic F-68 (PLF68 ) to study the controlled release of 5-FU using solvent evaporation method. The insertion of double bond in castor oil gives a versatile, chemical resistance, hardness, elongation, tensile strength properties and highly compatible PEUs. The prepared PEUs can be regarded as polymeric prodrugs because the drugs can be released by hydrolysis

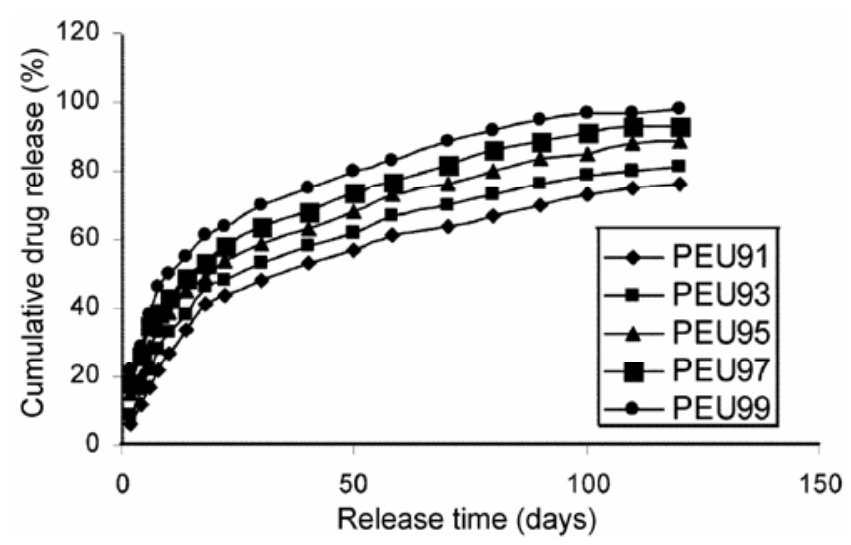

Figure 4. Drug release profiles of 5-FU from PEU microspheres prepared from curve (a) 1\% PLF-68;

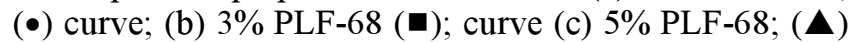
curve; (d) 7\% PLF-68; (घ) and curve (e) 9\% PLF-68 $(\diamond)$ at $37^{\circ} \mathrm{C}$. under mild conditions similar to those in biological systems. The microspheres produced exhibited encapsulation efficiencies up to $98 \%$ with spherical in nature and have wrinkled surfaces. The drug release mainly depends on amount of Pluronics present in the matrix. The PLF-68, which acts as hydrophilic filler in the formulations would help to control swelling and release of hydrophobic drug from the microspheres. It is also demonstrated that a hydrophilic and lipophilic balance of the matrices can be achieved by varying the ratio of two different diols to obtain the suitable PEU matrices for the release of a fast acting drug such as 5-FU. The formation and dissociation of hydrogen bonds result in swelling and collapse of PEUs and this special property can be used to control the delivery of drugs or other active molecules.

\section{Acknowledgements}

The authors thank the Department of Science and Technology, New Delhi (Ref. No SR/S1/OC-08/2005 dated 05-09-2005) for financial assistance and Center of Excellence in Polymer Science, Karnatak University, Dharwad, India, for providing the facilities.

\section{References}

1. www.polyurethane.org

2. Pinchuk L J 1994 Biomater. Sci. Polym. Ed. 6225

3. Haschke E, Sendijarevic V W S, Frisch K C and Hill G 1994 J. Elastomers. Plast. 2641

4. McNeill M E and Graham N B 1993 J. Biomater. Sci. Polym. Ed. 4(3) 305

5. Bae Y H and Kim S W 1993 Adv. Drug. Delivery Rev. 11109

6. Lin H B, Lewis K B, Leach-Scampavia D and Ratner B D 1993 J. Biomater. Sci. Polym. Ed. 4(3) 183

7. Marconi W, Galloppa A, Martinelli A and Piozzi A 1996 Biomate. 17(18) 1795

8. Magnini A, Busi E and Barbucci R 1994 J. Mater. Sci. Mater. Med. 5839

9. Alexandridis P, Nivaggioli T and Hatton T A 1995 Langmuir. 11(9) 1468

10. Booth C and Attwood D 2000 Macromol. Rapid. Commun. 21501

11. Riess G 2003 Prog. Polym. Sci. 281107

12. Kabanov AV, Batrakova E V, Alakhov V Y, $2002 \mathrm{~J}$. Control. Release 82189

13. Kabanov A V, Lemieux P, Vinogradov S V and Alakhov V Y 2002 Adv. Drug Deliv. Rev. 54223

14. Torchilin V P $2001 \mathrm{~J}$. Control. Release 73137

15. Allen C, Maysinger D and Eisenberg A 1999 Colloids Surf. B. 16(1-4) 3

16. Kwon G S and Okano T 1996 Adv. Drug Deliv. Rev. 21107 
17. Rosler A, Vandermeulen G W M and Klok H A 2001 Adv. Drug Deliv. Rev. 53(1) 95

18. Achaya K T 1971 J. Amer. Oil Chem. Soc. 48(11) 758

19. Nayak P L, Lenka S, Santosh K, Panda and Pattnaik T 1993 J. Appl. Polym. Sci. 47(6) 1089

20. Kirk-Olhmer 1964 Encyclopedia of chemical technology (New York: Wiley Publications), 2nd edn, vol. 4

21. McGraw-ME 1992 Encyclopedia of science and technology (New York: McGraw-Hill Publications), 7 th edn. vol. 14

22. Ogunniyi D S and Fakayejo W R O 1996 Iran. Polym. J. 5(1) 56

23. Qipeng G, Shixia F and Qingyu Z 1990 Eur. Polym. 26(11) 1177

24. Ghatage N D and Phadke V B 1967 J. Appl. Polym. Sci. 11(5) 629
25. Weiss E A 1983 Tropical agriculture series (Longman Scientific and Technical: Cambridge University Press)

26. Padma L N 2000 Polym. Rev. 40(1) 1

27. Yoho C W 1956 US Patent No 2769826

28. Friel R J 1962 US Patent No 3047520

29. Swanberg S T 1931 US Patent No 1787601

30. Namdev B S, Sairam M, Halligudi S B and Aminabhavi, T M 2007 J. Appl. Polym. Sci. 103779

31. Peppas N A and Ritger P L 1987 J. Control. Release 523

32. Colombo P, Bettini R, Catellani P L, Santi P and Peppas N A 1999 Eur. J. Pharm. Sci. 933

33. Han W W T and Stevens W F 2004 Drug Dev. Ind. Pharm. 30(4) 397

34. Xiao H and Tao L L 2005 Biomacromole. 6(4) 2131 